\title{
A suspected case of air embolism in endonasal surgery using $\mathrm{CO}_{2}$ laser
}

\author{
Seok-Hee Han, Byoung Sang Min, Ki Dong Kwon, and Tae Won Jung \\ Department of Anesthesiology and Pain Medicine, Cheongju St. Mary's Hospital, Cheongju, Korea
}

Laser surgery can cause air embolism due to the co-axial clearing/cooling gas flow, which is used to cool the distal end of the surgical equipment. We report a case in which air embolism was strongly suspected during endonasal surgery using $\mathrm{CO}_{2}$ laser.

A 46-year-old man $(178 \mathrm{~cm}, 95 \mathrm{~kg})$ underwent septoplasty and both turbinoplasty under general anesthesia. The patient's past medical history and pre-anesthetic evaluation are unremarkable.

Without premedication anesthesia was induced with thiopental $300 \mathrm{mg}$ and vecuronium $8 \mathrm{mg}$ IV injection and an internal diameter $7.5 \mathrm{~mm}$ tracheal tube was inserted. Anesthesia was maintained with sevoflurane $2.0-3.0$ vol\% and $1 \mathrm{~L} / \mathrm{min}$ each of oxygen and nitrous oxide $\left(\mathrm{N}_{2} \mathrm{O}\right)$. Mechanical ventilation was set to a tidal volume, respiration rate of $700 \mathrm{ml}$, $12 /$ min. End-tidal carbon dioxide $\left(\mathrm{ETCO}_{2}\right)$ and peak inspiratory pressure (PIP) were maintained at $38-42 \mathrm{mmHg}$ and $15 \mathrm{mmHg}$.

The patient was monitored with noninvasive blood pressure measurement (left upper arm, 3 minute intervals), ECG (lead II), pulse oximetry $\left(\mathrm{SpO}_{2}\right)$, and capnography.

During surgery the blood pressure, heart rate and $\mathrm{SpO}_{2}$ were maintained at $95-110 / 60-70 \mathrm{mmHg}, 55-60$ beats $/ \mathrm{min}$ and $99-100 \%$, respectively.

After completing the septoplasty, turbinoplasty on both turbinates was performed using a $\mathrm{CO}_{2}$ laser (Sharplan 30C, Lumenis $^{\mathrm{TM}}$, Santa Clara, CA, USA). Right turbinoplasty was finished and the operation proceeded on the left side when the end-tidal carbon dioxide concentration $\left(\mathrm{ETCO}_{2}\right)$ suddenly dropped to $20 \mathrm{mmHg}$, and soon, the $\mathrm{SpO}_{2}$ also fell to $82 \%$.
There were no significant changes in blood pressure, heart rate, ECG or PIP. The surgery was stopped, and the placement of endotracheal tube and the connection of anesthesia machine and breathing circuit were verified. Administration of sevoflurane and $\mathrm{N}_{2} \mathrm{O}$ was stopped and auscultation was performed on both lungs and the heart but there were no abnormalities. $\mathrm{ETCO}_{2}$ was still $20-22 \mathrm{mmHg}$, and $\mathrm{SpO}_{2}$ was $82-89 \%$. Arterial blood gas analysis performed at this time $\left(\mathrm{FiO}_{2}\right.$ 1.0) was as follows: $\mathrm{pH}$ (7.29), $\mathrm{pCO}_{2}$ (56 mmHg), $\mathrm{pO}_{2}(63$ $\mathrm{mmHg}), \mathrm{HCO}_{3}{ }^{-}$(26.9 mmol/L), and $\mathrm{SaO}_{2}(89 \%)$.

An air embolism was suspected, and the entrance of air was thought to have occurred at the nasal cavity; therefore, the nasal cavity was packed with gauzes and the surgery was completed. The patient was closely observed while continuing ventilation with $100 \%$ oxygen and rapid infusion of fluids. Approximately 7-8 minutes after stopping the surgery, the $\mathrm{SpO}_{2}$ and $\mathrm{ETCO}_{2}$ gradually started to increase and were restored to the original levels before the symptoms occurred in about 15 minutes. The portable chest radiograph taken at the time was unremarkable.

Approximately 10 minutes after the $\mathrm{SpO}_{2}$ and $\mathrm{ETCO}_{2}$ returned to normal, the patient regained consciousness. The patient recovered sufficiently from anesthesia and his vital signs and $\mathrm{SpO}_{2}$ were stable; therefore, pyridostigmine $5 \mathrm{mg}$ and glycopyrrolate $0.2 \mathrm{mg}$ was IV injected and the patient was extubated. The patient was moved to the recovery room and observed for an hour while administering oxygen ( $5 \mathrm{~L} / \mathrm{min}$ ) through a facial mask. There were no abnormalities observed; thus, the patient was sent to the general ward and discharged 2 days after the surgery.

Corresponding author: Seok-Hee Han, M.D., Department of Anesthesiology and Pain Medicine, Cheongju St. Mary's Hospital, 589-5, Jujungdong, Sangdang-gu, Cheongju 360-568, Korea. Tel: 82-43-219-8244, Fax: 82-43-219-8112, E-mail: h0813@medigate.net

(c) This is an open-access article distributed under the terms of the Creative Commons Attribution Non-Commercial License (http:// creativecommons.org/licenses/by-nc/3.0/), which permits unrestricted non-commercial use, distribution, and reproduction in any medium, provided the original work is properly cited. 
In this case, when the $\mathrm{SpO}_{2}$ and $\mathrm{ETCO}_{2}$ suddenly decreased, authors soon suspected air embolism. Situations that show such rapid changes when there had been stable vital signs during surgery can be malfunctioning in the anesthetic equipment or breathing circuit, acute pulmonary thromboembolism, air embolism, or acute myocardial infarction (AMI). First, the right connection and the operation of the anesthetic equipment and breathing circuit was immediately confirmed. Second, AMI could be excluded because the patient had no past history of hypertension or angina, and this change had suddenly appeared when the blood pressure and heart rate was stable and without ECG change. The possibility of acute pulmonary thromboembolism was also low since there had been no past history of deep vein thrombosis or atrial fibrillation, and the operation time was not long.

Fortunately, the patient recovered from the symptoms without special treatment other than stopping the surgery, ventilating with $100 \%$ oxygen, and rapid fluid infusion. Thus, the authors could not perform additional tests to confirm air embolism. If the symptoms had been more serious, a central venous catheter would have been inserted immediately for aspiration, and an echocardiography or CT scan would have been performed.

According to our literature survey, only one case of air embolism was reported in endonasal surgery related to using a $\mathrm{CO}_{2}$ laser [1]. The mechanism for air embolism related to the use of laser is known to be from the co-axial clearing/cooling gas flow used to cool the distal end of the laser equipment. In the case of Nd-YAG lasers, $200-400 \mathrm{ml} / \mathrm{min}$ of pressurized air is continually released at the surgical instrument tip, and the pressure produced at the tip has been measured over 500 mmHg [2]. The $\mathrm{CO}_{2}$ laser equipment (Sharplan 30C, Lumenis $^{\mathrm{TM}}$, Santa Clara, CA, USA) used in this case is also a structure where pressurized air is sent through the tube to cool the tip of the surgical equipment, but the flow and pressure have not been confirmed. The manufacturer has recommended that direct contact be avoided between the surgical equipment tip and tissues, and the clearing/cooling air flow should be properly controlled so that excessive pressure does not occur. In addition, when there is a high possibility of air embolism such as using laser inside a narrow body cavity, it is recommended that liquid be used as a coolant [3].

In this case, the sudden decrease of $\mathrm{ETCO}_{2}$ and $\mathrm{SpO}_{2}$ continued for approximately 15 minutes without accompanying hemodynamic changes, ECG changes, or millwheel murmur on auscultation may imply that the inflow of air was relatively slow and the amount was not large $[4,5]$.

In conclusion, endonasal laser surgery is relatively short and simple but air embolism can occur. To prevent air embolism in this surgery, the surgeon should avoid the direct contact of the surgical equipment tip to tissues, and the clearing/cooling gas flow should be lowered as much as possible. The anesthesiologist should keep in mind the possibility of air embolism and endeavor in its prevention and detection.

\section{References}

1. Osti D, Ferri E, Caggese G, Rinaldi S, Guberti A, Zoppellari R. Probable case of vascular air embolism during endonasal $\mathrm{CO}_{2}$ laser surgery. Minerva Anestesiol 2009; 75: 275-9.

2. Dullye KK, Kaspar MD, Ramsay MA, Giesecke AH. Laser treatment of endobronchial lesions. Anesthesiology 1997; 86: 1387-90.

3. Stoneback K. Systemic air embolism in laser operations. Ann Thorac Surg 1998; 66: 308.

4. Adornato DC, Gildenberg PL, Ferrario CM, Smart J, Frost EA. Pathophysiology of intravenous air embolism in dogs. Anesthesiology 1978; 49: 120-7.

5. Palmon SC, Moore LE, Lundberg J, Toung T. Venous air embolism: a review. J Clin Anesth 1997; 9: 251-7. 